\title{
Clinical and laboratory importance of detecting Helicobacter pylori coccoid forms for the selection of treatment
}

\author{
Nikita Gladyshev ${ }^{1}$, Maria Taame $^{2}$, Viacheslav Kravtsov ${ }^{3}$ \\ ${ }^{1}$ Medical Faculty, Saint Petersburg State University, Saint Petersburg, Russia \\ ${ }^{2}$ Institute of Public Health and Clinical Nutrition, University of Eastern, Kuopio, Finland \\ ${ }^{3}$ Department of Biology, S.M. Kirov Military Medical Academy, Saint Petersburg, Russia
}

Gastroenterology Rev 2020; 15 (4): 294-300

DOI: https://doi.org/10.5114/pg.2020.101557

Key words: Helicobacter pylori, coccoid, gastrointestinal tract, gastric ulcer, chronic gastritis, eradication therapy, spiral forms of Helicobacter pylori.

Address for correspondence: Prof. Viacheslav Kravtsov MD, PhD, Department of Biology, S.M. Kirov Military Medical Academy,

Saint Petersburg, Russia, phone: +79 602571 546, e-mail: kvyspb@mail.ru

\begin{abstract}
Helicobacter pylori grows and multiplies in the gastrointestinal tract (GIT) in about half of the world's population. The prevalence of diseases associated with this bacterium is steadily increasing, which makes it necessary to search for optimal therapy aimed at eradication of this bacterium. Such diseases, for example, include gastric ulcer (GU) and chronic gastritis (CG). Unfortunately, modern possibilities for eradication therapy do not always make it possible to cure patients, and relapses often occur if it is cured. Nowadays, a particular topical issue has arisen, which concerns the resistance of Helicobacter pylori to therapies, because the effectiveness of medication used in clinics decreases every year. One of the mechanisms favouring tolerance to antibiotics is the transformation into a different morphological form - coccoid. This form of the bacterium was discovered quite a long time ago. Nevertheless, the question of its importance in clinical practice remains open to this day. Modern studies are aimed at understanding the role of coccoid forms of $H$. pylori in the survival of the population of these bacteria and at clarifying their role in the pathogenesis of gastrointestinal diseases. It is not known whether it is necessary to evaluate the contamination of a given morphological form of a bacterium of the gastric mucosa in clinical practice and its influence on the development of diseases etc. This article presents an overview and analysis of modern ideas about $H$. pylori coccoid forms and answers to the main questions posed in the last 10 years regarding the study of coccoid forms. Additionally, our results present a comparison of expression of virulence factors in coccoid and spiral forms of $H$. pylori.
\end{abstract}

\section{Introduction}

Helicobacter pylori is a gram-negative microaerophilic bacterium that is present in the human body both in normal and pathological conditions. It is associated with various diseases of the gastrointestinal tract, such as acute and chronic gastritis, gastric ulcer, gastric lymphoma, and adenocarcinoma [1-5]. Although the bacterium is represented mainly in spiral form, it is capable of forming coccoid forms using the bacillary-coccoid transformation (BCT) process [6].

Since the discovery of these forms, various theories have been proposed regarding the survival, as well as function and role in the pathogenesis of $H$. pylori-associated gastrointestinal diseases. Despite the fact that significant progress has been made in understanding the morphology and vital functions of $H$. pylori and the pathogenesis of its diseases, we do not have a clear understanding of the importance of coccoid forms in the development of diseases, nor the importance of identifying them for the selection of rational eradication therapy.

In this article we discuss the most pressing topics that have accumulated over the past 10 years in order to come to an understanding of the importance of coccoid forms, namely:

1) the viability of coccoid forms;

2) the antibiotic resistance/tolerance of coccoid forms;

3) the BCT reversibility; 
4) the possibility of coccoid form transmission through faecal-oral route and inducing infectious process;

5) the virulence of coccoid forms compared to spirals.

\section{Coccoid viability}

The morphological form of $H$. pylori is represented by a spiral, under optimal conditions for vital activity. However, the bacterium can turn into a coccoid form under the influence of adverse conditions. This is a round morphological form of $H$. pylori approximately $0.5-1.4 \mu \mathrm{m}$ in size, which has even edges and a homogeneous cytoplasm on TEM (transmission electron microscopy) [7]. The presented criteria allow us to distinguish coccoid forms from dead bacteria, which have a similar form. Coccoid forms have a typical bacterial structure, represented by the cytoplasmic membrane, cytoplasm, and undamaged cell wall on TEM [8], which morphologically allows them to be classified as viable forms. Willen et al. revealed a high electron density in the cytoplasm of most coccoid forms, which has one or several vacuoles [7]. It was confirmed that these vacuoles contain a large amount of polyphosphate [9]. Polyphosphates can be used as an energy reserve in case of exogenous energy deficiency, to maintain the integrity of the main bacterial components, such as DNA, RNA, and structural proteins, which indicates the broad adaptive abilities of coccoid forms.

The coccoid forms of $H$. pylori can be divided into three types according to their structure: the degenerative coccoid form, which is a dying bacterium with a pyknotic structure; alive coccoid bacteria that can be grown in agar medium; and viable but non-cultivable (VBNC) H. pylori $[6,10,11]$. According to other data, the coccoid form is divided into two types: A and B. A type has an irregular shaped, rough surface with few flagella and an indistinct cytoplasmic membrane that obscures much of the intracytoplasmic structure, and these bacteria also tend to adhere to each other and thus are considered to be dead cells of $H$. pylori. B type shows a smoother surface with tightly encircled flagella, and comparatively clear membrane structure. B type has a better-maintained intracytoplasmic structure and thus is considered as a living cell [12].

Coccoid forms, besides their viability, can also be distinguished on the basis of their metabolic abilities. Sarafnejad et al. [13] showed by using flow cytometry method the presence of metabolic activity of coccoid forms. The study used Rhodamine 123 , which absorbs viable microorganisms with greater intensity. Coccoid forms showed the ability to absorb Rhodamine 123 but with less activity than spiral form, which was explained in the study by the fact that this morphological form exhibits less metabolic activity than spiral forms. Furthermore, Loke et al. confirmed that the metabolism of coccoid forms, when compared with spiral forms, is significantly slowed but not stopped. Among proteins that were much less enriched in coccoid forms, 35 were enzymes involved in various metabolic pathways. Conversely, the content of the other 13 metabolic enzymes was increased. Based on a comparison of the relative abundance of key metabolic proteins expressed in two morphologically differentiated forms of $H$. pylori, coccoid forms were less metabolically active than the spiral forms, but the activity of most enzymes was still maintained at the basal level, while the activity of the others was increased [9].

Slowing down the metabolism is an important mechanism necessary for survival in extreme conditions, such as lack of oxygen, energy substrates, etc. [14]. These data speak in favour of the fact that coccoid form, from the point of view of its metabolic potential, is not only a viable morphological form, but also a special existence strategy that the bacterium chooses to live in adverse conditions. Conversely, the activity of RecA enzyme, which starts the so-called SOS system that participates in the DNA repair of cells, increases [9]. This result is contradictory and is interpreted in two ways. Its increase may be due to damage to the DNA of the bacterium, which leads to death, or to the increased reparative potential of coccoid form, and it facilitates the ability to recombine. One more ambiguous result should be noted, namely a decrease in activity of enzymes (RecN, RecR) that are responsible for DNA repair, the damage of which is caused by oxidative and acid stress $[9,15,16]$. This phenomenon can be caused by an increase in the resistance of the coccoid form to oxygen radicals and acid ions or a decrease of their release due to a slower metabolism and, consequently, less need for DNA repair or having limited reparative ability of the coccoid compared to the spiral forms. An increase in the activity of proteins responsible for chemotaxis, colonisation, and response to "stressful" factors was observed against the background of a decrease in another regulator responsible for the same functions in the same study. The number of structural subunits of urease B (UreB) and auxiliary proteins (UreF) were reduced in coccoid form, which explains the observation of a decrease in the urease activity of this morphological form and failure of urease test in determining the presence of Helicobacter pylori in gastric mucosa. MreB protein, which increases division activity, is actively synthesised in coccoid forms [9]. It is thought that MreB may play a role in the survival of coccoid forms.

The ability to form biofilms, in which the two above morphotypes coexist, also indicates the viability of coccoid forms. Moreover, coccoid forms of $H$. pylori possess increased capacity to aggregate into monomicrobial bacterial clusters surrounded by a thick matrix of exopolysaccharide [17]. 


\section{The tolerance of coccoid forms to antibiotics and the human immune system}

The increasing H. pylori resistance to previously efficacious antibiotic regimens is of great concern and requires modification of therapeutic strategies [18]. For example, the antibiotic clarithromycin has been shown to be almost completely ineffective in studies in Poland and Turkey [19, 20]. Additionally, H. pylori showed resistance to metronidazole in Polish patients [20]. Thus, it is important to learn and explore the factors that can influence successful eradication treatment of $H$. pylori infection. Baris et al. and Szadkowski et al. have found different factors that can be involved in antibiotic resistance treatment from genotype, gender, age, smoking habits, and the medication itself, to the resistance of bacteria $[19,20]$.

One of the reasons for ineffective therapy may relate to antibiotic-resistant coccoid form of $H$. pylori. Coccoid form of $H$. pylori usually contributes to antibiotic tolerance and makes the bacterium less accessible for eradication. Figura et al. found that one of the factors negatively affecting eradication was the presence of coccoid forms $(p=0.0008)$ [21]. Additionally, Kravtsov et al. also showed in their study that the majority of 14 patients whose eradication was ineffective had the highest degree of contamination with coccoid form of $H$. pylori [22]. In addition, the coccoid form makes recovery more difficult, and causes relapse and epidemic transmission [23]. In a study where $21 \mathrm{bi}$ opsies were taken from patients who had eradication, H. pylori was isolated in culture in seven biopsies, while gene expression methods revealed viable $H$. pylori cells in most biopsies. Scanning electron microscopy (SEM), meanwhile, showed cluster coccoid bacteria located in a microbial biofilm, suggesting that coccoid forms may also contribute to bacterial tolerance to antibiotics used [17]. Faghri et al. [24] tested the sensitivity of viable coccoid forms to three antibiotics and showed that amoxicillin exerted the greatest bactericidal effect in vitro on spiral forms of $H$. pylori; however, $2 \times$ minimal inhibitory concentration (MIC) did not have a bactericidal effect on coccoid forms. Another study found that coccoid forms were resistant to amoxicillin concentration more than 10-fold compared to the MIC [25], confirming a higher antibiotic tolerance of these morphological forms.

The mechanisms of coccoid resistance to eradication are not well understood, but it can be assumed that bacteria acquire this property by reducing surface area, slowing down metabolism, and expressing "stress genes". One of these genes is spoT. The spot gene is a potential global transcriptional regulator for growth and persistence of
H. pylori and, apparently, a critical regulator of stress reactions that affects energy metabolism, detoxification, and protein fate $[26,27]$. It is believed that the spoT gene is necessary for the survival of $H$. pylori in the coccoid form under conditions that bacteria may experience during eradication or when in an environment different from living environment [14, 27]. The rapid accumulation of guanosine tetraphosphate (ppGpp) and inhibition of stable RNA synthesis are clear signs of a stringent response. In fact, it is assumed that ppGpp binds and modifies the affinity of RNA polymerase to various promoters, such as those associated with adaptation to adverse conditions, and it has a significant effect on controlling the expression of virulence genes in a wide variety of pathogenic bacteria [28, 29]. In addition, spoT plays an important role in the avoidance of bacteria from macrophage elimination and plays a significant role in colonisation of $H$. pylori in mice without inducing a strong immune response [26, 27]. Poursina et al. found in his study that expression of the spoT gene was significantly reduced in spiral forms of H. pylori, while the corresponding expression of the gene was increased in coccoid forms [30].

There is also evidence of stability of coccoid forms due to changes in the composition of the cell wall. The fact is that the transition to coccoid forms correlates with the accumulation of the $\mathrm{N}$-acetyl-D-glucosaminyl$\beta(1,4)$-N-acetylmuramyl-L-Ala-D-Glu (GM-dipeptide) motif. This modification may play a role in resistance to bactericidal agents, such as amoxicillin, that affect the cell wall [31]. Costa et al. [32] demonstrated that the activation of $(\gamma)$-glutamyl diaminopimelate-endopeptidase during the morphological transition into dipeptide monomers in H. pylori leads to increased conversion that is similar to the sporulation in Bacillus sphaericus. This phenomenon leads to the genesis of resistant coccoid forms and endospores in H. pylori and B. sphaericus, respectively. The high resistance of these forms can be due to various cell wall modifications in coccoid forms and loss of antibiotic targets in these forms.

Moreover, Chaput et al. demonstrated the ability of H. pylori coccoid cells to avoid detection by the immune system due to significant modification of the cell wall peptidoglycan, which did not have IL-8 stimulating activity in the epithelial cells of the stomach. Thus, H. pylori in a state of VBNC may be able to avoid or modulate the host's reaction and thus persist in the human stomach [31].

We strongly recommend that gastroenterologists accept the $H$. pylori bacillary coccoid dualism phenomenon and do not persist in prescribing a second course of eradication for coccoid forms of $\mathrm{H}$. pylori. We hope that the BCT of $H$. pylori will be considered in the next Maastricht agreements. 


\section{Bacillary coccoid transformation and its reversibility}

As mentioned earlier, the spiral H. pylori can turn into coccoid under the influence of adverse conditions, such as a change in $\mathrm{pH}, \mathrm{pO}_{2}[14,33,34]$ aging, aerobiosis [35], temperature increase, or antibiotic exposure [24]. Spiral H. pylori can turn into coccoid form, and the conditions must be suboptimal in order to transform into VBNC [11]. However, bacillary coccoid transformation (BCT) can occur in the absence of adverse conditions, for example during prolonged cultivation [36]. There are two possible explanations for this process. According to the first, the concentration of substances that can stimulate BCT increases with prolonged cultivation of bacteria in the colony, thereby increasing the population of coccoid forms [37]. Another explanation is based on the impossibility to simulate the conditions observed in gastric mucosa in vitro, and due to the accumulation of toxic metabolites (when compliant to parameter "suboptimal conditions"), spiral forms turn into coccoid forms over time. This once again confirms that BCT is an active process necessary for the survival of bacteria.

During the process of transformation, $H$. pylori goes through several stages: S (spiral) form, U form, and C (coccoid) form (Figure 1). These stages are preceded by morphological changes.

The initial stage of $H$. pylori transformation into the coccoid form is accompanied by condensation of the protoplasmic matrix and an increase in the periplasm on one side of the microorganism (usually at the pole opposite to the basal complex of the flagellum). The increase in the volume of the periplasmic space leads to stretching of the cell wall, and displacement of the protoplasmic matrix to the periphery and the accumulation of dense material, which leads to the formation of U-shaped cells ( $U$ forms) [8]. Furthermore, $U$ forms are transformed into coccoid forms with an increase in the protoplasmic cylinder and formation of a double membrane system [38]. It is worth noting that $U$ forms are only an intermediate stage in the process of turning a helix into a coccoid, and not separate morphological forms $[14,39,40]$. $U$ forms of $H$. pylori retain the polar membrane associated with the flagellar basal complex [8]. However, not all intermediate forms have a sufficient number of flagella and a sufficient level of metabolic activity, which limits their ability to move [40].

An important fact is that the most active induction of BCT occurs in the most virulent strains [41], which suggest the need to measure the activity of the BCT at least in order to have an idea about the virulence of the bacteria that caused the disease and the possible outcome of the development of the disease.

Clinically significant data suggest that different concentrations of amoxicillin, clarithromycin, metronidazole, and erythromycin, i.e. major $A B$ in the eradication scheme, can induce the formation of coccoid forms [24, 42]. It follows that not all $H$. pylori microorganisms are completely destroyed after eradication therapy; probably, some of them can be converted into coccoid forms and thus become resistant to antibacterial drugs. This would explain the failure of treatment and the recurrence of infection $[43,44]$.

The spread of $H$. pylori in an alimentary tract is also happening due to coccoid forms, which are highly resistant to adverse environmental conditions [45, 46], and possibly contributes to the recurrence of infection [42]. Despite the fact that data were obtained on the transformation of some coccoid forms back into a spiral [47], the ability to reverse the process of coccoid transformation is little studied, but it is not denied that this phenomenon is possible [46]. This process is called "resuscitation" in the literature [48]. In the case of possible return of coccoid to the spiral form, there is a possibility of inducing an active infection on the surface of gastric mucosa.

Therefore, it has been suggested that the transformation of bacteria into coccoid form reduces their metabolic rate and causes minor changes in the physiological processes of the bacterium. These changes, in turn, make it impossible to restore the bacterial signs that contribute to the colonisation and infection of gastric mucosa. The coexistence of both forms (coccoid and spiral) in different environmental conditions in this case explains the survival strategy of the bacterium [49].

\section{The ability of coccoid forms to transmit infection}

When the reversibility of BCT in the human body is finally proven, then the question will arise about the

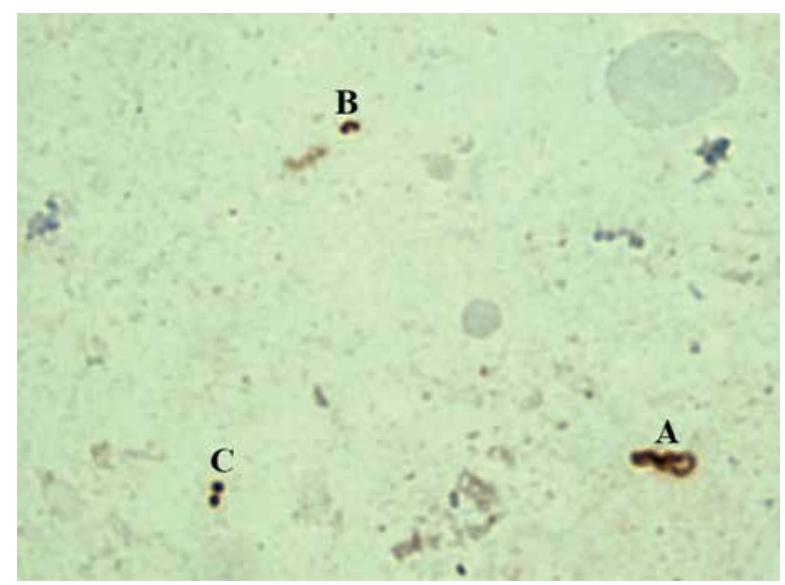

Figure 1. Immunocytochemical examination of smears-prints obtained from the antrum of the stomach. A - spiral form, B - U form, and C coccoid form 
possibility of spreading infection using coccoid forms. Krzyżek and Gościniak proposed a hypothetical model for the transmission of coccoid forms of $\mathrm{H}$. pylori and their induction of the infectious process [37]. H. pylori infection occurs by swallowing contaminated water, food, or contact with an infected person. The body is infected mainly by coccoid forms, because the bacterium can exist in this form for long time in the environment [50]. Furthermore, when stimulated by the resuscitation process by the gastric microbiota, which secretes substances like Al-2, coccoid forms turn into mobile spiral forms that colonise the mucous membrane, form biofilms, and contribute to the development of diseases [37]. Subsequently, BCT inductors accumulate in the biofilm, which contribute to the formation of coccoid forms and the release some of them with faeces into the environment $[37,51]$, ensuring the spread though faecal-oral route. Then, when environmental conditions change (accumulation of BCT inducers, decrease in nutrient levels, etc.), coccoid forms in the stomach turn back into spirals, contributing to the progression of the disease and the search of new niches in the gastric environment.

\section{Virulence and possible role in the development of gastric cancer}

The expression of coccoid virulence factors in comparison with spiral forms has not been studied enough, but according to the available data it can be suggested that coccoid forms, if not more, then certainly are no less virulent than spiral forms [9].

Despite the decrease in the BabA factor affecting the adhesive abilities, there are still no significant differences in the index of adhesive abilities between the coccoid and the spiral forms [23].
An increase in the expression of some factors of the cag PAl apparatus shows that the coccoid form is not inert but can infect humans and is likely to play an important role in chronic diseases of the stomach. This fact is confirmed by a clinical case, in which an 89-year-old patient had chronic active gastritis, which was characterised by the presence of only coccoid forms in the coolant [52]. While VacA is an inducer of apoptosis, CagA can lead to excessive cell proliferation [53, 54]. Consequently, an uneven decrease in the expression of the corresponding genes can lead to excessive division or excessive apoptosis. The expression of the cagA and vacA genes was lower in the $H$. pylori coccoid form than in the spiral form, but the decrease in vacA expression was greater than that of cagA [55]. These results suggest that the abundant contamination with coccoid forms may be one of the factors that increase the risk of developing gastric cancer. The abundance of expression of tumour necrosis factor $\alpha$ (TNF- $\alpha$ )-inducing protein (Hps) with proven carcinogenicity, as shown in Table I [9, 56-63]. Increases in coccoid forms, and also indirectly affects their stability in gastric mucosa, reducing the acidity of the environment [9].

The increased expression of anti-apoptotic protein "survivin" in coccoid forms plays a role in the development of carcinogenesis [23], and possibly increases the risk of stomach cancer formation contaminated with coccoid forms.

\section{Conclusions}

Summarising the findings:

- based on the data presented above, we assume that coccoid forms are viable morphological forms;

- coccoid forms of $H$. pylori are tolerant to the most effective antibiotics used in eradication therapy;

Table I. Expression of H. pylori virulence factors in coccoid forms compared with spiral forms. "+" - greater expression, “-" - lower expression. *The presence of opposite results in different studies i.e. +/- , which may require additional detailed study

\begin{tabular}{|c|c|c|}
\hline Factor & Expression & Function \\
\hline CagA & $-[56]$ & Violation of intracellular signalling systems \\
\hline CagE* $^{*}$ & $+[9],[57]$ & Key factors of secretory system type IV. Caga translocation into the cell [59] \\
\hline CagV & $+[9]$ & \\
\hline VacA & $-[55]$ & Induction of vacuolization and apoptosis of cells, reduction of T-lymphocyte activity \\
\hline BabA & $-[57]$ & Adhesion molecule \\
\hline YidC & $+[9]$ & Estimated translocase component \\
\hline Hps & $+[9]$ & Inductor for the expression of TNF and chemokines \\
\hline RocF & $-[58]$ & Hydrolysis of arginine with the formation of urea and ornithine [60] \\
\hline Tip- $\alpha$ & $-[58]$ & $\begin{array}{l}\text { Moved to cells, Tip- } \alpha \text { induces the expression of TNF- } \alpha, \text { IL- } 6 \text { and several chemokine genes by } \\
\text { activating NF- } \kappa B \text { [61-63] }\end{array}$ \\
\hline
\end{tabular}


- the question about BCT reversibility requires more extensive research;

- coccoid forms of $H$. pylori may be responsible for the faecal-oral transmission in people, possibly turning back into spirals after successful eradication;

- coccoid forms of $H$. pylori are virulent and possibly increase the risk of gastric cancer in patients with abundant BCT activity.

These findings prove the need to evaluate coccoid form of $\mathrm{H}$. pylori contamination of the gut in clinical practice in order to prevent the spread of infection, to prescribe rational antibiotic therapy (change the pattern of eradication therapy), and to clarify the prognosis of the disease.

\section{Conflict of interest}

The authors declare no conflict of interest.

\section{References}

1. Amieva MR, El-Omar EM. Host-bacterial interactions in Helicobacter pylori infection. Gastroenterology 2008; 134: 306-23.

2. Franco AT, Israel D, Washington M, et al. Activation of beta-catenin by carcinogenic Helicobacter pylori. Proc Natl Acad Sci USA 2005; 102: 10646-51.

3. Hosseini E, Poursina F, Wiele VD, et al. Helicobacter pylori in Iran: a systematic review on the association of genotypes and gastroduodenal diseases. J Res Med Sci 2012; 17: 280-92.

4. Kusters JG, van Vliet AH, Kuipers EJ. Pathogenesis of Helicobacter pylori infection. Clin Microbiol Rev 2006; 19: 449-90.

5. Safaei H, Tavakkoli H, Mojtahedi A, et al. Correlation of cagA positive Helicobacter pylori Infection with clinical outcomes in Alzahra hospital, Isfahan, Iran. JRMS 2008; 13: 196-201.

6. Andersen LP, Rasmussen L. Helicobacter pylori-coccoid forms and biofilm formation. FEMS Immunol Med Microbiol 2009; 56: 112-5.

7. Willén $R$, Carlén $B$, Wang $X$, et al. Morphologic conversion of helicobacter pylori from spiral to coccoid form: scanning (SEM) and transmission electron microscopy (TEM) suggest viability. Upsala J Med Sci 2000; 105: 31-40.

8. Reshetnyak VI, Reshetnyak TM. Significance of dormant forms of Helicobacter pylori in ulcerogenesis. World J Gastroenterol 2017; 23: 4867-78.

9. Loke MF, Ng CG, Vilashni Y, et al. Understanding the dimorphic lifestyles of human gastric pathogen Helicobacter pylori using the SWATH-based proteomics approach. Sci Rep 2016; 6: 26784.

10. Andersen RN, Ganeshkumar N, Kolenbrander PE. Helicobacter pylori adheres selectively to Fusobacterium spp. Oral Microbiol Immunol 1998; 13: 51-4.

11. Azevedo NF, Almeida C, Cerqueira L, et al. Coccoid form of Helicobacter pylori as a morphological manifestation of cell adaptation to the environment. Appl Environ Microbiol 2007; 73: 3423-7.

12. Sato F, Saito N, Konishi K, et al. Ultrastructural observation of Helicobacter pylori in glucose-supplemented culture media. J Med Microbiol 2003; 52: 675-9.
13. Sarafnejad A, Siavoshi F, Safaralizadeh R, et al. Assessment of Helicobacter pylori viability by flow cytometry. Iran J Public Health 2007; 36: 50-4.

14. Mouery K, Rader BA, Gaynor EC, et al. The stringent response is required for Helicobacter pylori survival of stationary phase, exposure to acid, and aerobic shock. J Bacteriol 2006; 188: 5494-500.

15. Wang G, Lo LF, Maier RJ. The RecRO pathway of DNA recombinational repair in Helicobacter pylori and its role in bacterial survival in the host. DNA Repair 2011; 10: 373-9.

16. Wang G, Maier RJ. Critical role of RecN in recombinational DNA repair and survival of Helicobacter pylori. Infection Immun 2008; 76: 153-60.

17. Cellini L, Grande R, di Campli E, et al. Dynamic colonization of Helicobacter pylori in human gastric mucosa. Scand J Gastroenterol 2008; 43: 178-85.

18. Malfertheiner P, Megraud F, O'Morain CA, et al. Management of Helicobacter pylori infection - the Maastricht V/ Florence Consensus Report. Gut 2017; 66: 6-30.

19. Baris Y, Koseoglu H, Coskun Y, et al. Comparison between different first-line therapy protocols in eradicating Helicobacter pylori in a region with high clarithromycin resistance. Gastroenterol Rev 2018; 13: 150-6.

20. Szadkowski A, Zemlak M, Muszyński J. Effectiveness of Helicobacter pylori eradication established on the basis of examination of antibiotic resistance of the bacteria. Gastroenterol Rev 2018; 13: 93-8.

21. Figura N, Moretti E, Vaglio L, et al. Factors modulating the outcome of treatment for the eradication of Helicobacter pylori infection. New Microbiol 2012; 35: 335-40.

22. Kravtsov V, Mikhailova I, Grukgin Y, et al. High degree of gastric mucosa colonization with coccoid forms of helicobacter reduce the efficiency of its eradication. Int J Curr Res 2016; 8: 32757-60.

23. Liu ZF, Chen CY, Tang W, et al. Gene-expression profiles in gastric epithelial cells stimulated with spiral and coccoid Helicobacter pylori. J Med Microbiol 2006; 55: 1009-15.

24. Faghri J, Poursina F, Moghim S, et al. Morphological and bactericidal effects of different antibiotics on Helicobacter pylori. Jundishapur J Microbiol 2014; 7: e8704.

25. Berry V, Jennings K, Woodnutt G. Bactericidal and morphological effects of amoxicillin on Helicobacter pylori. Antimicrobial Agents Chemother 1995; 39: 1859-61.

26. Zhou YN, Coleman WG, Yang Z, et al. Regulation of cell growth during serum starvation and bacterial survival in macrophages by the bifunctional enzyme SpoT in Helicobacter pylori. J Bacteriol 2008; 190: 8025-32.

27. Sun Y, Li X, Li W, et al. Proteomic analysis of the function of spot in Helicobacter pylori anti-oxidative stress in vitro and colonization in vivo. J Cell Biochem 2012; 113: 3393-402.

28. Wells DH, Gaynor EC. Helicobacter pylori initiates the stringent response upon nutrient and $\mathrm{pH}$ downshift. J Bacteriol 2006; 188: 3726-9.

29. Charity JC, Blalock LT, Costante-Hamm MM, et al. Small molecule control of virulence gene expression in Francisella tularensis. PLoS Pathogens 2009; 5: e1000641.

30. Poursina F, Fagri J, Mirzaei N, et al. Overexpression of spoT gene in coccoid forms of clinical Helicobacter pylori isolates. Folia Microbiol 2018; 63: 459-65. 
31. Chaput C, Ecobichon C, Cayet N, et al. Role of AmiA in the morphological transition of Helicobacter pylori and in immune escape. PLoS Pathogens 2006; 2: e97.

32. Costa K, Bacher G, Allmaier G, et al. The morphological transition of helicobacter pylori cells from spiral to coccoid is preceded by a substantial modification of the cell wall. J Bacteriol 1999; 181: 3710-5.

33. Donelli G, Matarrese P, Fiorentini C, et al. The effect of oxygen on the growth and cell morphology of Helicobacter pylori. FEMS Microbiol Letters 1998; 168: 9-15.

34. Benaissa M, Babin P, Quellard N, et al. Changes in Helicobacter pylori ultrastructure and antigens during conversion from the bacillary to the coccoid form. Infect Immun 1996; 64: 2331-5.

35. Bode G, Mauch F, Malfertheiner P. The coccoid forms of Helicobacter pylori. Criteria for their viability. Epidemiol Infect 1993; 111: 483-90.

36. Mouery K, Rader BA, Gaynor EC, et al. The stringent response is required for Helicobacter pylori survival of stationary phase, exposure to acid, and aerobic shock. J Bacteriol 2006; 188 5494-500.

37. Krzyżek P, Gościniak G. A proposed role for diffusible signal factors in the biofilm formation and morphological transformation of Helicobacter pylori. Turk J Gastroenterol 2018; 29: 7-13.

38. O'Rourke J, Bode G. Morphology and ultrastructure. In: Helicobacter pylori: Physiology and Genetics. Mobley HLT, Mendz GL, Hazell SL (eds.). ASM Press, Washington (DC) 2001.

39. Khomeriki SG, Morozov IA. The role of coccoid forms of Helicobacter pylori in pathogenetic mechanisms and persistence of Helicobacter infection. Russian J Gastroenterol Hepatol Coloproctol 2001; 11 Suppl 13: 99-102.

40. Williams CL. Helicobacter pylori: bacteriology and laboratory diagnosis. J Infect 1997; 34: 1-5.

41. Krzyżek P, Biernat M, Gościniak G. Intensive formation of coccoid forms as a feature strongly associated with highly pathogenic Helicobacter pylori strains. Folia Microbiol 2019; 64: 273-81.

42. Sarem M, Corti R. Role of Helicobacter pylori coccoid forms in infection and recrudescence. Gastroenterol Hepatol 2016; 39: 28-35.

43. Citterio B, Casaroli A, Pierfelici L, et al. Morphological changes and outer membrane protein patterns in Helicobacter pylori during conversion from bacillary to coccoid form. New Microbiol 2004; 27: 353-60.

44. Roe HI, Son SH, Oh HT, et al. Changes in the evolution of the antigenic profiles and morphology during coccoid conversion of Helicobacter pylori. Korean J Internal Med 1999; 14: 9-14.

45. She FF, Lin JY, Liu JY, et al. Virulence of water-induced coccoid Helicobacter pylori and its experimental infection in mice. World J Gastroenterol 2003; 9: 516-20.

46. Cellini L, Allocati N, Angelucci D, et al. Coccoid Helicobacter pylori not culturable in vitro reverts in mice. Microbiol Immuno 1994; 38: 843-50.

47. Richards CL, Buchholz BJ, Ford TE, et al. Optimizing the growth of stressed Helicobacter pylori. J Microbiol Methods 2011; 84 174-82.

48. Ramamurthy T, Ghosh A, Pazhani GP, et al. Current perspectives on viable but non-culturable (VBNC) pathogenic bacteria. Front Public Health 2014; 2: 103.
49. Duś I, Dobosz T, Manzin A, et al. Role of PCR in Helicobacter pylori diagnostics and research: new approaches for study of coccoid and spiral forms of the bacteria. Postepy Hig Med Dosw 2013; 67: 261-8.

50. West AP, Millar MR, Tompkins DS. Effect of physical environment on survival of Helicobacter pylori. J Clin Pathol 1992; 45: 228-31.

51. Kravtsov VYu, Grukhin YuA. Immunocytochemical study of Helicobacter pylori in the mucosae of the gastric antrum and rectum. Bull Exp Biol Med 2012; 153: 348-50.

52. Balakrishna JP, Filatov A. Coccoid forms of Helicobacter pylori causing active gastritis. Am J Clin Pathol 2013; 140 Suppl 1: A101.

53. Marusawa H. Mechanisms of $\mathrm{H}$. pylori infection-induced gastric carcinogenesis. Gan to kagaku ryoho. Cancer Chemother 2010; 37: 23-7.

54. Tanaka H, Yoshida M, Azuma T. The role of CagA in H. pylori infection. Nippon Rinsho 2009; 67: 2245-9.

55. Li N, Han L, Chen J, et al. Proliferative and apoptotic effects of gastric epithelial cells induced by coccoid Helicobacter pylori. J Basic Microbiol 2013; 53: 147-55.

56. Sisto F, Brenciaglia MI, Scaltrito MM, et al. Helicobacter pylori: ureA, cagA and vacA expression during conversion to the coccoid form. Int J Antimicrobial Agents 2000; 15: 277-82.

57. Poursina F, Faghri J, Moghim S, et al. Assessment of cagE and babA mRNA expression during morphological conversion of Helicobacter pylori from spiral to coccoid. Curr Microbiol 2013; 66: 406-13.

58. Müller SA, Pernitzsch SR, Haange SB, et al. Stable isotope labeling by amino acids in cell culture based proteomics reveals differences in protein abundances between spiral and coccoid forms of the gastric pathogen Helicobacter pylori. J Proteom 2015; 126: 34-45.

59. Kumar N, Shariq M, Kumar A, et al. Analyzing the role of CagV, a VirB8 homolog of the type IV secretion system of Helicobacter pylori. FEBS Open Bio 2017; 7: 915-33.

60. Kim SH, Sierra RA, McGee DJ, et al. Transcriptional profiling of gastric epithelial cells infected with wild type or arginase-deficient Helicobacter pylori. BMC Microbiol 2012; 12: 175.

61. Watanabe T, Tsuge H, Imagawa $\mathrm{T}$, et al. Nucleolin as cell surface receptor for tumor necrosis factor- $\alpha$ inducing protein: a carcinogenic factor of Helicobacter pylori. J Cancer Res Clin Oncol 2010; 136: 911-21.

62. Suganuma M, Watanabe T, Yamaguchi K, et al. Human gastric cancer development with TNF-alpha-inducing protein secreted from Helicobacter pylori. Cancer Letters 2012; 322: 133-8.

63. Tang CL, Hao B, Zhang GX, et al. Helicobacter pylori tumor necrosis factor- $\alpha$ inducing protein promotes cytokine expression via nuclear factor-kappaB. World J Gastroenterol 2013; 19: 399-403.

Received: 19.09 .2019

Accepted: 14.01 .2020 